\title{
REVENUE AND PRODUCTION MANAGEMENT IN A MULTI-ECHELON SUPPLY CHAIN
}

\author{
Alireza Kabirian \\ Ahmad Sarfaraz \\ Mark Rajai \\ Department of Manufacturing Systems Engineering and Management \\ California State University-Northridge \\ Northridge, CA 91330, USA
}

\begin{abstract}
This paper models a supply chain problem and employs simulation-based optimization to analyze it. The model represents a manufacturer of multiple products from multiple raw materials that has control over the price of the products. The decisions to be optimized in the model are ordering policies of raw materials, inventory control of finished goods, manufacturing capacity of each product, and prices set on the products. The uncertainties involved are lead times of ordering inventory and the demand of the products. We consider the case of periodic review of raw materials and finished goods inventories on discrete time. The objective is to find the best configuration of the system to maximize profit. We show how simulation-based optimization could find the best configuration through an example.
\end{abstract}

\section{INTRODUCTION}

Coordination of organizational functions and among different enterprises working together to provide goods and services to the customers is a subject studied in the literature of supply chain management. Supply chain activities transform natural resources, raw materials, and components into a finished product that is delivered to the end customer. The main operations involved in a supply chain are sourcing, procurement, conversion, and logistics; however models developed for supply chains may surpass operational issues and encompass other departments of an enterprise such as marketing, accounting or research and development. Even though there is no single model of supply chain to include all complexities of operations involved, there has been a variety of models and analysis tools developed to address certain types or parts of a supply chain. We attempt to develop one such model in this paper and analyze it through simulation-based optimization.

As an example of an application of our model, consider an imaginary small business such as IceCream Masters (ICM). The business produces different types of ice cream by mixing and processing different ingredients such as milk, sugar, nuts, and saffron. ICM has a weekly production schedule in which production level of each type of ice cream is determined at the end of each week considering production capacities, available food ingredients, and demand. It takes one week to complete a production order placed at the end of the prior week-end. Once the production for an order is complete, the ice cream packages are stored in refrigerators for the retail customers and ice-cream distributors to buy in the following week. ICM has observed that even though the weekly demands are random, average demand of each ice cream per week is negatively correlated with the price that ICM asks for that type of ice-cream. In addition to price tags put on the products, ICM must also find the best policies of production schedule and ordering of raw materials. The raw materials are bought from different suppliers. Purchase orders are placed at the end of each week based on inventory levels of milk, sugar, nuts, etc. However, it takes a random time for the order to be filled. The stochastic model developed in this paper tries to find optimal market- 
ing, inventory and production-control policies simultaneously to maximize the average total weekly profit of a company such as ICM.

There are different streams of research related to this paper. This research addresses the problem of finding the best prices of some products in manufacturing operations management; however the problem has been extensively studied in revenue management especially for service operations such as airlines, hotels, etc. See Talluri and van Ryzin (2004) for a comprehensive review of revenue management.

The coordination of pricing and inventory replenishment has received considerable attention in the literature (Ardalan 1995). This topic, starting with the work of Whitin (1955) who analyzed the news vendor problem with price-dependent demand, has been the focus of many papers (Chao et al. 2008). Federgruen and Heching (1999) characterized the optimal inventory and pricing policy as a base-stock list-price policy for both the finite and infinite horizon problems. Chen and Simchi-Levi $(2004 a, b)$ extended the work in Federgruen and Heching (1999) by considering a fixed setup cost for ordering. Optimal policies of joint pricing and replenishment for both finite and infinite horizons have also been derived. Sharkey (2011) derived optimal pricing and network flow decisions. In most of these works, only one stream of inventory policy of one product is modeled along with pricing decisions, ignoring downstream of the materials required to produce these products in a supply chain. The main reason stochastic models of simultaneously integrating pricing, upstream and downstream inventory policies, and production capacity constraints have gained less attention is because the models can easily get intractable analytically and difficult to optimize under realistic assumptions. Simulation-based optimization is a strong alternative that has less restriction in accommodating realistic assumptions about the model and the set of decisions needing simultaneous optimization.

Over the past couple of decades, many new methods have been developed for solving optimization models for stochastic systems when the objective function and/or some functions in the constraints of the model are not available in closed-form; the only way to get an idea about the values that these functions take is to estimate them by simulating the stochastic system. In the literature, this class of optimization methods is called simulation-based optimization. A review of these methods could be found in $\mathrm{Fu}(2002)$ and $\mathrm{Fu}$, Glover, and April (2005).

This paper is organized as follows. In Section 2, we develop a model for the type of supply chain considered in this paper. Section 3 applies the model on a case study and analyzes the results. Section 4 concludes the paper.

\section{MODELING}

\subsection{The Problem}

The problem of interest is about a simple supply chain in which a manufacturer is trying to coordinate marketing function with production and inventory management to maximize profit (see Figure 1). Here, we construct an optimization model for the problem.

There are $n$ products that are manufactured from $m$ Raw Materials (RMs). A unit of product $j$ requires $m_{i j}$ units of RM $i$.

The manufacturer has a retail outlet to sell the products to customers. We assume the manufacturer can set a static price $u_{j}$ on product $j$ for foreseeable future. However, the demand of each product is a function of the price. The higher the price asked by the manufacturer, the less the average demand will be in the market. We discretize time in our model by breaking each year into a number of periods. The periods could be days, weeks, or months as examples. Let $D_{j}^{t}$ be the demand of product $j$ in period $t$. We assume, for simplicity, $D_{j}^{t}$ for $t=1,2, \ldots$ be independent and identically distributed (iid) random variables. However, the expected value of $D_{j}^{t}$ is assumed to be a known function of $u_{j}$, that is $\mathbb{E}\left(D_{j}^{t}\right) \equiv f_{j}\left(u_{j}\right)$. In addition, assume the demand of different products are independent, that is $D_{j}^{t}$ for $j=1,2, \ldots, n$ are inde- 
pendent. Since we use simulation to analyze the supply chain, it should be easy to extend the model and relax these two independency assumptions in a different research.

The finished goods are stored and wait in line in the retail outlet for the customers to pick up. We assume there is a limited space available to store product $j$ in the outlet which can accommodate a maximum of $S_{j}$ units of product $j$ at any time. If this maximum is hit, the associated product could no longer be stored in the outlet. Since the production system directly transfers the manufactured products to the outlet, this means if maximum capacity to hold a product in the outlet is hit, the production of this good must halt. The length of product $j$ 's queue in the outlet fluctuates every period; let $Y_{j}^{t}$ be the queue length at the end of period $t$.

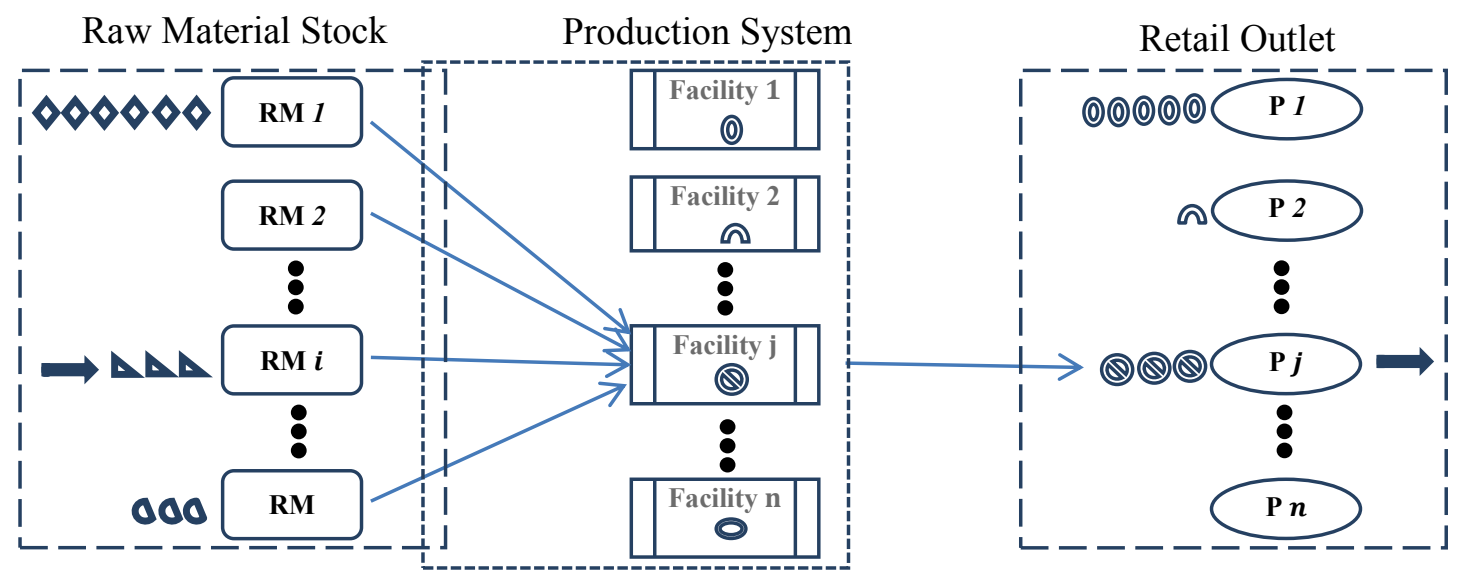

Figure 1: Supply chain with Raw Material (RM) Stock, Production Facilities and Retail Outlet of the Products $(\mathrm{P})$

The production system has separate manufacturing facilities for each product. The production capacity of product $j$ per period, denoted by $C_{j}$, is assumed limited. Product $j$ could be manufactured up to $C_{j}$ provided that enough raw materials are available. The supply chain follows a Kanban-based pull policy of production. At the end of period $t$, the level of finished product $j$ (i.e. $Y_{j}^{t}$ ) is observed in the outlet; if $Y_{j}^{t} \leq s_{j}$, a Kanban is raised that signals the production facility $j$ is allowed to schedule producing up to $S_{j}-Y_{j}^{t}$ units in the next period. Indeed, the finished goods inventory of product $j$ in the outlet has a twobin $\left(s_{j}, S_{j}\right)$ inventory control policy in which the level $s_{j}$ is production trigger of product $j$ which is set at less than or equal to $S_{j}$. Products manufactured in a period are transferred directly to the relevant queue in the outlet at the end of the period; i.e these recently manufactured products may not be used to satisfy the demand in the same period.

The stock of raw materials also has a separate queue for each RM. The length of queue of RM $i$ at the end of period $t$ is denoted by $X_{i}^{t}$. The ordering policy in this stock follows a two-bin $\left(s_{i}{ }_{i}, S^{\prime}{ }_{i}\right)$ for RM $i$ where $S_{i}{ }_{i}$ is the maximum storage capacity and $s^{\prime}{ }_{i}$ is the ordering trigger. If $X_{i}^{t} \leq s^{\prime}{ }_{i}$, an order of size $S^{\prime}{ }_{i}-X_{i}^{t}$ is placed with the supplier of RM $i$ at the end of period $t$. The time between placement of the order till arrival of RM, lead time, is assumed to be a discrete random variable with a known distribution. Let $L_{i}$ be the lead time of RM $i$ and assume it is independent of the period of ordering. We also assume the lead times of different RMs are independent for simplicity. Again since simulation is used for analysis, it should be easy to relax these two assumptions about lead times. The RMs ordered arrive at the end of period $L_{i}$ after ordering, join the RM queue immediately and will be available to production system in the following period. 


\section{Kabirian, Sarfaraz, and Rajai}

The production quantity of each product in each period is constrained by production signals from the outlet at the end of previous period, available raw materials and a production policy. If multiple production facilities have the go-ahead signal of production from the outlet and raw materials are available to produce any or a combination of them, then the production policy should determine the production quantity of each product. Different policies could be used. For instance, a policy may assign production quota of each product proportional to the strength of production signals $\left(S_{j}-Y_{j}^{t}\right)$. Another policy may determine production quantities based on RM levels solely. Here we use yet another simple policy as follows. We assume the products are prioritized based on anticipated profitability with product 1 having the highest priority and product $n$ the lowest. First the production policy allows product 1 to be produced as much as possible, then product 2 with the RMs left over and so forth. Let $P_{j}^{t}$ be production quantity of product $j$ in period $t$. This policy means $P_{j}^{t}$ 's are computed using the following recursive equation in which $\mathbb{I}[\mathcal{A}]$ is an indicator function that takes 1 if condition $\mathcal{A}$ is satisfied and zero otherwise:

$$
P_{j}^{t}=\mathbb{I}\left[Y_{j}^{t-1} \leq s_{j}\right] \min \left\{C_{j}, S_{j}-Y_{j}^{t-1}, \min _{i}\left\{\left(X_{i}^{t-1}-\sum_{k=1}^{j-1} P_{k}^{t} m_{i k}\right) / m_{i j}\right\}\right\} \forall j, t .
$$

The finished goods inventory levels are updated at the end of each period after adding produced units to the stock and accounting for satisfied demand. The recursive equation is $Y_{j}^{t}=Y_{j}^{t-1}+P_{j}^{t}-\min \left\{Y_{j}^{t-1}, D_{j}^{t}\right\} \forall j, t$ where $\min \left\{Y_{j}^{t-1}, D_{j}^{t}\right\}$ is the satisfied demand of product $j$ in period $t$ from the ready-to-go units of the product at the end of prior period, if any. This apparently assumes a lost-sale scenario if available inventory is not enough to satisfy demand. Similarly, the level of each RM must be updated. This needs defining $Q_{i}^{t}$ as the number of units of RM $i$ arrived to the stock at the end of period $t$. The order for these $Q_{i}^{t}$ units must have been placed at the end of period $t-l_{i}$ where $l_{i}$ is the observed value of lead time of this RM for this particular order. Then $X_{i}^{t}=X_{i}^{t-1}+Q_{i}^{t}-\sum_{j=1}^{n} P_{j}^{t} m_{i j} \forall i, t$.

We consider six sets of decision variables for the supply chain model:

- Sales price of each product: $u_{j} \forall j=1,2, \ldots, n$

- Manufacturing capacity of each production facility: $C_{j} \forall j=1,2, \ldots, n$

- Storage capacity of each product in the outlet: $S_{j} \forall j=1,2, \ldots, n$

- Production trigger of each product: $s_{j} \forall j=1,2, \ldots, n$

- Storage capacity of each RM in the RM stock: $s^{\prime}{ }_{i} \forall i=1,2, \ldots, m$

- Ordering trigger of each RM in the RM stock: $S_{i}^{\prime} \forall i=1,2, \ldots, m$

The objective function of the model maximizes the expected total profit per period of the steady-state system. The function is the difference between expected sales revenues of all products and the sum of expected costs. We consider a number of costs for the system as follows:

- Purchasing raw materials

- Holding raw materials

- Ordering costs of raw materials

- Overhead cost of maintaining storage capacities of raw materials

- Overhead cost of maintaining manufacturing capacities of production facilities

- Holding finished goods in the outlet

- Overhead cost of maintaining storage capacities of finished goods in the outlet

We need additional notations to define the objective function mathematically. Let $r_{i}$ be the unit cost of purchasing raw material $i$. For simplicity, we assume these costs are independent of time and fixed (i.e. no discount, etc). Let $o_{i}$ be ordering cost of RM $i$ independent of time or order size. Let $h_{i}$ be variable holding cost per period of a unit of RM $i$ in the RM stock or as Work-In-Process (WIP) in the production 
facilities. Also let $H_{j}$ be the variable holding cost of a unit of product $j$ in the outlet per period. Often times, the holding costs are assumed to be a function of the money the company has invested in acquiring the inventory. We assume $h_{i}=r_{i} I$ where $I$ is a discount rate per period. We also assume the variable holding cost of a product in the outlet to be a fraction of the value of the RMs used to produce a unit of the product. That is, we let $H_{j}=\sum_{i=1}^{m} h_{i} m_{i j}$. Finally, let $c_{i}, c_{j}^{\prime}$, and $c_{j}^{\prime \prime}$ be the overhead cost per unit per week to maintain a storage capacity of RM $i$ in the RM stock, manufacturing capacity of product $j$ in the production system, and a storage capacity of product $j$ in the outlet respectively. These costs must be paid irrespective of the fluctuating utilization factor of these capacities over time.

Let $\pi^{t}$ be the total profit made in period $t$. Using a cash method of accounting, the total profit function is

$$
\begin{aligned}
\pi^{t}=\sum_{j=1}^{n}\left\{u_{j}\right. & \left.\min \left\{D_{j}^{t}, Y_{j}^{t-1}\right\}-c_{j}^{\prime \prime} S_{j}-c_{j}^{\prime} C_{j}-H_{j} Y_{j}^{t-1}\right\} \\
& -\sum_{i=1}^{m}\left\{h_{i} X_{i}^{t-1}+c_{i} S^{\prime}{ }_{i}+\mathbb{I}\left[X_{i}^{t} \leq s^{\prime}{ }_{i}\right]\left(o_{i}+\left(S^{\prime}{ }_{i}-X_{i}^{t}\right) r_{i}\right)\right\}
\end{aligned}
$$

The sequence $\left\{\mathbb{E}\left(\pi^{t}\right)\right\}_{t=1,2, \ldots}$ is an stochastic process. If the business turns out unprofitable, no product should be produced, no cost is paid, and no revenue is generated; therefore the series is bounded below by zero profit. Theory of Constraints implies that every system has some boundaries for growth. Even though we let optimization process find the best limits of capacities in the system which theoretically means the capacities of storages and production can grow unboundedly, no such supply chain can sell infinite units of the products in the market. Demand will not go to infinity even if the prices are set to zero. This means the expected profit is always bounded above. Since the expected profit sequence is abounded up and down, it may not diverge. So it must either converge or oscillate. We assume simply that oscillation is not the case for this sequence.

The complete model of the supply chain is the following:

$$
\begin{gathered}
\max _{u_{j}, C_{j}, s_{j}, S_{j}, s^{\prime}{ }_{i}, S^{\prime}{ }_{i} \forall i, j \quad} \quad \lim _{t \rightarrow \infty} \mathbb{E}\left(\pi^{t}\right) \\
\text { Subject to: } \\
0 \leq s_{j} \leq S_{j} \leq \mathcal{O}_{j} \forall j \\
0 \leq s^{\prime}{ }_{i} \leq S^{\prime}{ }_{i} \leq \mathcal{M}_{i} \forall i \\
0 \leq C_{j} \leq \mathcal{P}_{j} \forall j \\
0 \leq u_{j} \leq \mathcal{U}_{j} \forall j \\
C_{j}, s_{j}, S_{j}, s^{\prime}{ }_{i}, S^{\prime}{ }_{i} \text { are integers }
\end{gathered}
$$

where $\mathcal{O}_{j}, \mathcal{M}_{i}, \mathcal{P}_{j}, \mathcal{U}_{j}$ are upper bounds defined to cap the decision variables.

\subsection{Solving the Model}

To the best of our knowledge, an analytical method does not exist in the literature to solve the optimization model developed in the previous section. Different complexities exist in this model that makes finding a closed-form solution to the model difficult. On one side in the RM stock, the queues of RMs are dependent on each other. Once a product needs to be produced, the production system pulls out some raw materials from each queue simultaneously. On the upstream, there is another set of lines, one for each product in the outlet. We are interested in analyzing both sets of queues along with examining production system under generic assumptions about inventory policies and the two uncertain parameters, namely demands and lead times.

Fortunately, discrete-event simulation can always be employed in these situations. Fixing some values for the decision variables, one can develop a simulation model and run the system for hundreds or 


\section{Kabirian, Sarfaraz, and Rajai}

thousands of periods and get an estimate of profit per week in the long run. Then, if an optimization algorithm is linked to the simulation model to change the values of the decision variables and have the system with each set of decision variables simulated, an estimated (near) best optimum may be found. This is what the literature of simulation calls simulation-based optimization which is our approach to solve the supply chain model developed in the previous section.

Since we assumed a periodic review of production and inventory management on discrete time, the discrete-event model could easily be developed in spreadsheet. We recommend using Microsoft Excel to develop such an spreadsheet because it is commonly-used for different data analyses in any organization which means not much training is required to build the model and also there is no need to pay for and learn to use a commercial simulation software. Another strong motivation to use Excel is that it already has a built-in optimization tool called Excel Solver. Even though the Solver is not as powerful or efficient as commercial optimization packages available for simulation optimization to handle big or very complex models, but it is still a handy and easy-to-use optimization method especially when simulation models could be developed in spreadsheets. In the next section, we show how a simulation model of a case study is developed in Excel and we use Excel Solver to find (near) optimal solutions.

\section{CASE STUDY}

We use a case study in this section to show how the model could be solved and analyzed using Simulation-based Optimization.

\subsection{Case Data}

Consider a manufacturer of 2 products from 3 RMs that uses weeks as periods of production and marketing planning. The data of RMs in this case are provided in Table 1.

Table 1: Data of raw materials used in the case

\begin{tabular}{|c|c|c|c|c|c|c|c|}
\hline \multirow[b]{2}{*}{$\mathbf{R M}$} & \multicolumn{2}{|c|}{ RM Requirements } & \multirow[b]{2}{*}{$\begin{array}{c}\text { Purchase } \\
\text { cost/unit } \\
\boldsymbol{r}_{\boldsymbol{i}}\end{array}$} & \multirow{2}{*}{$\begin{array}{c}\text { Holding } \\
\text { cost/unit/ } \\
\text { week } \\
\boldsymbol{h}_{\boldsymbol{i}}\end{array}$} & \multirow[b]{2}{*}{$\begin{array}{c}\text { Ordering } \\
\text { cost/order } \\
\boldsymbol{o}_{\boldsymbol{i}}\end{array}$} & \multirow{2}{*}{$\begin{array}{c}\text { Storage } \\
\text { cap } \\
\text { cost/unit/ } \\
\text { week } \\
\boldsymbol{c}_{\boldsymbol{i}}\end{array}$} & \multirow[b]{2}{*}{$\begin{array}{c}\text { Cap upper } \\
\text { bound } \\
\boldsymbol{M}_{\boldsymbol{i}}\end{array}$} \\
\hline & $\begin{array}{l}\text { Product } \\
1 \boldsymbol{m}_{\boldsymbol{i 1}} \text { : }\end{array}$ & $\begin{array}{l}\text { Product } \\
2: \boldsymbol{m}_{\boldsymbol{i} \mathbf{2}}\end{array}$ & & & & & \\
\hline$i=1$ & 3 & 2 & $\$ 1.00$ & $\$ 0.50$ & $\$ 500.00$ & $\$ 0.05$ & 30,000 \\
\hline$i=2$ & 2 & 1 & $\$ 2.00$ & $\$ 0.50$ & $\$ 500.00$ & $\$ 0.05$ & 30,000 \\
\hline$i=3$ & 0 & 2 & $\$ 1.00$ & $\$ 0.50$ & $\$ 500.00$ & $\$ 0.05$ & 30,000 \\
\hline
\end{tabular}

For $=1,2,3$, the lead time of RM $i$ is assumed to be a random variable that takes 1,2, and 3 weeks with probabilities $0.5,0.4$, and 0.1 respectively.

Linear demand is a popular assumption in modeling the relationship of price and demand in economics. We assume the average demand of each product is a linear function of price; specifically $\mathbb{E}\left(D_{1}^{t}\right)=$ $3,000-100 u_{1}$ and $\mathbb{E}\left(D_{2}^{t}\right)=6,000-150 u_{2}$. Since a negative average demand is meaningless, we let the price upper bounds $\mathcal{U}_{1}=30$ and $\mathcal{U}_{2}=40$. We assume $D_{j}^{t}$ follows a normal distribution with mean $\mathbb{E}\left(D_{j}^{t}\right)$ and standard deviation $\mathbb{E}\left(D_{j}^{t}\right) / 5$. Since the products are discrete, we round the demand observations to the nearest integer and use 0 for any negative random value.

Some more data about the two products used in the case studied here are summarized in Table 2.

\subsection{Simulation and Optimization Methodologies}

We developed a discrete-event simulation model in Microsoft Excel 2010. The spreadsheet was linked to Excel Solver. The Solver has three solution algorithms: Simplex for linear programs, a gradient-based 
nonlinear program, and an evolutionary algorithm. The user can select which algorithms he/she wants to use. For our case, we used the Evolutionary Algorithm with the following parameters: a Convergence of 0.000001, Mutation of 0.075, Population Size of 1000, and a Maximum Time Without Improvement of 300 seconds. We ran the simulation for 1100 weeks, through away the first 100 weeks to warm-up simulation and averaged the total profit over the last 1000 weeks. Our tests with more than 1000 weeks of net data revealed that our results are robust. Table 3 shows part of the final simulation spreadsheet obtained after it took Solver a little over an hour to stop.

Table 2: Data of the two products

\begin{tabular}{|c|c|c|c|c|c|}
\hline & $\begin{array}{c}\text { Holding } \\
\text { Cost/week } \\
\boldsymbol{H}_{\boldsymbol{j}}\end{array}$ & $\begin{array}{c}\text { Manufacturing Cap } \\
\text { Cost/unit/week } \\
\boldsymbol{c}_{\boldsymbol{j}}^{\prime}\end{array}$ & $\begin{array}{c}\text { Storage cap } \\
\text { cost/unit/week } \\
\boldsymbol{c}_{\boldsymbol{j}}^{\prime \prime}\end{array}$ & $\begin{array}{c}\text { Manufacturing } \\
\text { Cap Upper } \\
\text { Bound } \\
\boldsymbol{\mathcal { P }}_{\boldsymbol{j}}\end{array}$ & $\begin{array}{c}\text { Storage Cap } \\
\text { Upper Bound } \\
\boldsymbol{O}_{\boldsymbol{j}}\end{array}$ \\
\hline $\boldsymbol{j}=\mathbf{1}$ & $\$ 3.00$ & $\$ 1.00$ & $\$ 0.05$ & 2,000 & 90,000 \\
\hline $\boldsymbol{j}=\mathbf{2}$ & $\$ 3.00$ & $\$ 1.00$ & $\$ 0.05$ & 2,000 & 90,000 \\
\hline
\end{tabular}

Table 3: Partial spreadsheet of Discrete-event simulation of the supply chain for the optimal decision variables

\begin{tabular}{|c|c|c|c|c|c|c|c|c|c|c|c|c|}
\hline \multirow{2}{*}{$\begin{array}{c}\text { Week } \\
t\end{array}$} & \multicolumn{2}{|c|}{$\begin{array}{l}\text { Production } \\
\text { Quantities }\end{array}$} & \multicolumn{3}{|c|}{ RM Order Placed } & \multicolumn{3}{|c|}{ Ending Inventory of RMs } & \multicolumn{2}{|c|}{ Demand } & \multicolumn{2}{|c|}{$\begin{array}{l}\text { Ending Stock } \\
\text { of Products }\end{array}$} \\
\hline & $P_{1}^{t}$ & $P_{2}^{t}$ & $i=1$ & $i=2$ & $i=3$ & $X_{1}^{t}$ & $X_{2}^{t}$ & $X_{3}^{t}$ & $D_{1}^{t}$ & $D_{2}^{t}$ & $Y_{1}^{t}$ & $Y_{2}^{t}$ \\
\hline 0 & 0 & 0 & 0 & 0 & 0 & 1,000 & 1,000 & 1,000 & 880 & 1,802 & 200 & 250 \\
\hline 1 & 333 & 0 & 21,681 & 12,675 & 13,663 & 1 & 334 & 1,000 & 523 & 1,291 & 333 & 0 \\
\hline 2 & 0 & 0 & 0 & 0 & 0 & 1 & 13,009 & 14,663 & 707 & 2,033 & 0 & 0 \\
\hline 3 & 0 & 0 & 0 & 0 & 0 & 21,682 & 13,009 & 14,663 & 857 & 1,889 & 0 & 0 \\
\hline 4 & 713 & 1,799 & 5,737 & 0 & 0 & 15,945 & 9,784 & 11,065 & 814 & 2,138 & 713 & 1,799 \\
\hline 5 & 713 & 1,799 & 5,737 & 6,450 & 7,196 & 15,945 & 6,559 & 7,467 & 795 & 1,457 & 713 & 2,141 \\
\hline 101 & 713 & 1,799 & 11,050 & 0 & 0 & 10,632 & 9,784 & 4,293 & 626 & 1,926 & 1,073 & 2,855 \\
\hline 102 & 713 & 1,799 & 5,737 & 6,450 & 7,196 & 15,945 & 6,559 & 7,467 & 719 & 1,825 & 1,067 & 2,829 \\
\hline 103 & 713 & 1,799 & 0 & 0 & 0 & 10,208 & 3,334 & 3,869 & 940 & 1,895 & 840 & 2,733 \\
\hline 104 & 713 & 1,799 & 0 & 6,450 & 7,196 & 4,471 & 6,559 & 7,467 & 937 & 1,215 & 713 & 3,317 \\
\hline 105 & 713 & 1,165 & 15,943 & 0 & 0 & 5,739 & 3,968 & 5,137 & 1,030 & 2,479 & 713 & 2,003 \\
\hline 1,091 & 713 & 1,799 & 0 & 6,450 & 0 & 10,208 & 6,559 & 11,065 & 813 & 1,883 & 713 & 2,175 \\
\hline 1,092 & 713 & 1,799 & 11,474 & 0 & 7,196 & 10,208 & 3,334 & 7,467 & 881 & 2,008 & 713 & 1,966 \\
\hline 1,093 & 713 & 1,799 & 0 & 6,450 & 0 & 4,471 & 6,559 & 3,869 & 791 & 1,362 & 713 & 2,403 \\
\hline 1,094 & 713 & 1,165 & 0 & 0 & 5,928 & 2 & 3,968 & 8,735 & 725 & 1,418 & 713 & 2,150 \\
\hline 1,095 & 0 & 0 & 10,206 & 0 & 0 & 11,476 & 10,418 & 14,663 & 734 & 1,832 & 0 & 318 \\
\hline 1,096 & 713 & 1,799 & 5,737 & 5,816 & 0 & 15,945 & 7,193 & 11,065 & 1,091 & 1,109 & 713 & 1,799 \\
\hline 1,097 & 713 & 1,799 & 5,737 & 0 & 7,196 & 15,945 & 9,784 & 7,467 & 687 & 1,901 & 739 & 1,799 \\
\hline 1,098 & 713 & 1,799 & 0 & 6,450 & 0 & 10,208 & 6,559 & 11,065 & 555 & 1,192 & 897 & 2,406 \\
\hline 1,099 & 713 & 1,799 & 11,474 & 0 & 7,196 & 10,208 & 3,334 & 7,467 & 844 & 1,416 & 766 & 2,789 \\
\hline 1,100 & 713 & 1,799 & 5,737 & 0 & 0 & 15,945 & 109 & 3,869 & 774 & 1,922 & 713 & 2,666 \\
\hline
\end{tabular}


Kabirian, Sarfaraz, and Rajai

\subsection{Results}

The optimal solution found by Solver are provided in Tables 4, 5,6, and 7.

Table 4: Optimal values of products-related decision variables

\begin{tabular}{|c|c|c|c|c|}
\hline & $\begin{array}{c}\text { Production Trig- } \\
\text { ger (Smaller bin) } \\
\text { Product }\end{array}$ & $\begin{array}{c}\text { Holding Capacity } \\
\text { (bigger bin) } \\
\boldsymbol{S}_{\boldsymbol{j}}\end{array}$ & $\begin{array}{c}\text { Manufacturing } \\
\text { capacity/week }\end{array}$ & $\begin{array}{c}\text { Sales Price } \\
\boldsymbol{C}_{\boldsymbol{j}}\end{array}$ \\
\hline $\boldsymbol{j}=\mathbf{1}$ & 3,095 & 3,097 & 713 & $\$ 22.29$ \\
\hline $\boldsymbol{j}=\mathbf{2}$ & 6,692 & 10,883 & 1,799 & $\$ 28.54$ \\
\hline
\end{tabular}

Table 5: Optimal values of raw materials-related decision variables

\begin{tabular}{|c|c|c|}
\hline RM & $\begin{array}{c}\text { Ordering Trigger } \\
\text { (Smaller bin) } \\
\boldsymbol{s}^{\prime}{ }_{\boldsymbol{i}}\end{array}$ & $\begin{array}{c}\text { Holding Capacity } \\
\text { (bigger bin) } \\
\boldsymbol{S}_{\boldsymbol{i}}\end{array}$ \\
\hline $\boldsymbol{i}=\mathbf{1}$ & 17,421 & 21,682 \\
\hline $\boldsymbol{i}=\mathbf{2}$ & 9,218 & 13,009 \\
\hline $\boldsymbol{i}=\mathbf{3}$ & 9,699 & 14,663 \\
\hline
\end{tabular}

Table 6: Sample average of optimal costs per week

\begin{tabular}{|l|c|c|c|c|c|c|}
\hline $\begin{array}{c}\text { RMs Pur- } \\
\text { chase Costs }\end{array}$ & $\begin{array}{c}\text { Variable } \\
\text { Holding } \\
\text { Costs of } \\
\text { RMs }\end{array}$ & $\begin{array}{c}\text { Variable } \\
\text { Holding } \\
\text { Costs of } \\
\text { Products }\end{array}$ & $\begin{array}{c}\text { Ordering } \\
\text { Costs of } \\
\text { RMs }\end{array}$ & $\begin{array}{c}\text { Storage- } \\
\text { Capacity } \\
\text { Costs of } \\
\text { RMs }\end{array}$ & $\begin{array}{c}\text { Production- } \\
\text { Capacity } \\
\text { Costs }\end{array}$ & $\begin{array}{c}\text { Storage- } \\
\text { Capacity } \\
\text { Costs of } \\
\text { products }\end{array}$ \\
\hline$\$ 4,138.70$ & $\$ 2,880.35$ & $\$ 7,328.66$ & $\$ 767.50$ & $\$ 2,467.68$ & $\$ 2,512.39$ & $\$ 698.99$ \\
\hline
\end{tabular}

Table 7: Sample average of optimal revenues and total profit per week

\begin{tabular}{|c|c|}
\hline Sales Revenue of all products & Total Profit \\
\hline$\$ 59,845.70$ & $\$ 19,051.43$ \\
\hline
\end{tabular}

If only our model were to maximize expected revenue and ignore production and inventory constraints, the optimal prices should have been $3,000 /(2 * 100)=\$ 15.00$ for product 1 and $6,000 /(2 * 150)=\$ 20.00$ for product 2 . These numbers are found by maximizing the quadratic functions $u_{1} \mathbb{E}\left(D_{1}^{t}\right)=u_{1}\left(3,000-100 u_{1}\right)$ and $u_{2} \mathbb{E}\left(D_{2}^{t}\right)=u_{2}\left(6,000-150 u_{2}\right)$. The near optimal values found for profit-maximization model of the supply chain provided in Table 4 are significantly higher. This is because higher prices lead to smaller weekly demands and lower costs.

Another interesting observation that is partly revealed in Table 3 is that in most weeks simulated, optimization produces at the maximum capacity of production. More precisely, the average utilization factor of production capacities were $95.2 \%$ for product 1 and $87.0 \%$ for product 2 . This might be because we chose a hefty $\$ 1.00$ overhead cost per unit per week for production capacity. The high near optimal Production Capacity Cost of $\$ 2,512.39$ (compared to other cost items) shown in Table 6 puts more support to our hypothesis. 
The average raw materials, work-in-process and finished goods in the system are shown in Table 8 below.

Table 8: Average units of RM, Work-In Process, and Finished Goods in the Chain

\begin{tabular}{|c|c|c|c|c|}
\hline \multicolumn{2}{|c|}{$\begin{array}{c}\text { Average Units of Raw Material stored } \\
\text { in RM stock and as Work-In Process }\end{array}$} & \multicolumn{2}{c|}{$\begin{array}{c}\text { Average Units of Finished Goods } \\
\text { Stored in the Outlet per Week }\end{array}$} \\
\hline $\boldsymbol{i}=\mathbf{1}$ & $\boldsymbol{i}=\mathbf{2}$ & $\boldsymbol{i}=\mathbf{3}$ & $\boldsymbol{j}=\mathbf{1}$ & $\boldsymbol{j}=\mathbf{2}$ \\
\hline 11,159 & 6,812 & 7,785 & 782 & 2,150 \\
\hline
\end{tabular}

We expected to see smaller queue lengths than what is shown in Table 7. Of course one way to shorten these waiting lines is to increase holding costs to move towards Just-In-Time. However, this may come at the expense of less than optimal profit that could be gained without forcing extra holding costs.

\section{CONCLUSION}

In this paper, we modeled a supply chain including a manufacturer of multiple products from multiple raw materials that tries to optimize inventory and production policies as well as managing revenue. We showcased how the model could be applied and solved using simulation-based optimization. Our results suggest that simulation-based optimization is a powerful method of finding a near optimum design of a stochastic system and is a good alternative when analytical methods fail.

A number of research directions are open. The methodology used here could be applied in other scenarios including stochastic production times, backlogging of unsatisfied orders, or discount on volume of purchase for the raw materials. Another direction is to model the system in a way that dynamic programming could be applied on or as a multi-phase queue.

\section{REFERENCES}

Ardalan, A. 1995. "A Comparative Analysis of Approaches for Determining Optimal Price and Order Quantity When a Sale Increases Demand." European Journal of Operational Research 84:416-430.

Chao, X., H. Chen, and S. Zheng. 2008. "Joint Replenishment and Pricing Decisions in Inventory Systems with Stochastically Dependent Supply Capacity." European Journal of Operational Research 191:142-155.

Chen, X., and D. Simchi-Levi. 2004a. "Coordinating Inventory Control and Pricing Strategies with Random Demand and Fixed Ordering Cost: the Finite Horizon Case." Operations Research 52:887-896.

Chen, X., and D. Simchi-Levi. 2004b. "Coordinating Inventory Control and Pricing Strategies with Random Demand and Fixed Ordering Cost: the Infinite Horizon Case." Operations Research 52:698723.

Federgruen, A., and A. Heching. 1999. "Combining Pricing and Inventory Control under Uncertainty." Operations Research 47:454-475.

Fu, M. C. 2002. "Optimization for Simulation: Theory vs. practice.” INFORMS Journal on Computing 14:192-215.

Fu, M. C., F. W. Glover, and J. April. 2005. "Simulation optimization: A review, new developments, and applications". In Proceedings of the 2005 Winter Simulation Conference, edited by M. E. Kuhl, N. M. Steiger, F. B. Armstrong, and J. A. Joines, 83-95. Piscataway, New Jersey: Institute of Electrical and Electronics Engineers, Inc.

Sharkey, T.C. 2011. "Network flow problems with pricing decisions." Optimization Letters 5(1):71-83.

Talluri, K.T., and G.J. Ryzin. 2004. The Theory and Practice of Revenue Management. Kluwer.

Whitin, T.M. 1955. "Inventory Control and Price Theory." Management Science 2:61-80. 


\section{AUTHOR BIOGRAPHIES}

ALIREZA KABIRIAN is currently an Assistant Professor of Engineering Management at California State University-Northridge. He has also taught in the College of Business and Public Policy at the University of Alaska-Anchorage previously. Alireza has received his $\mathrm{PhD}$ from Iowa State University in Industrial Engineering in 2009. He has a number of research interests including simulation optimization and operations management. He can be contacted at a_kabirian@yahoo.com.

AHMAD SARFARAZ is a Professor of Engineering Management at Department of Manufacturing System Engineering and Management, California State University, Northridge. His research interests are in Operation Research, AHP, Facilities Layout and Location, and Economic Analysis. He is author or coauthor of numerous publications and consults in Facilities Planning and Lean Manufacturing, System Analysis, Expert Systems, and Operations Modeling. He has received San Fernando valley's Engineer's Council Merit Award for the year 2002. He can be reached at sarafarz@csun.edu.

MARK RAJAI is a full-time faculty of engineering management at California State University (CSUN)Northridge. Dr. Mark Rajai is founder, Chairman of the Board Directors and President of the International Association of Journals and Conferences (IAJC). Prior to founding IAJC, he founded two U.S.-based start-up companies and served as CEO and president of both companies. He also founded two well-known International journals. He has numerous journals and conference publications. He can be reached at mark.rajai@csun.edu. 